\title{
Implementation of policy, system and environment changes in early childhood education settings
}

\author{
Charlotte V. Farewell* ${ }^{*}$, Jamie N. Powers, Emily Maiurro, Sharon Scarbro, Jennie Quinlan and Jini Puma
}

*Correspondence:
charlotte.
farewell@cuanschutz.edu
Rocky Mountain Prevention
Research Center, Colorado
School of Public Health,
University of Colorado
Denver, 12477 East 19th
Ave, Building 406 Room 104,
Aurora, CO 80045, USA

${ }^{*}$ Correspondence:

Rocky Mountain Prevention

Research Center, Colorado

School of Public Health,

University of Colorado

Ave, Building 406 Room 104

Aurora, CO 80045, USA

\begin{abstract}
Background: Changing Policy, System, and Environmental features focused on physical activity and healthy eating behaviors can play a key role in obesity prevention strategies in early childhood education settings because of their broad reach and because they can be sustained over time. The primary aims of this study were to examine the implementation and sustainability of health-promoting PSE changes after facilitation of an innovative strategic planning process in child care settings.

Methods: The evidence-based policy, system, and environment change process is a strategic planning tool derived from intervention mapping that involves convening interdisciplinary wellness teams at child care settings to implement healthy eating and physical activity-related policy changes. The process was conducted with 43 wellness teams representing 68 child care centers.

Results: The average number of health-promoting evidence-based changes implemented across all child care centers was 5.07; the most common type of changes were environment changes. Overall, $42 \%$ of changes were partially implemented and $47 \%$ of changes were fully implemented at 6 months. Head Start wellness teams implemented 1.52 fewer health-promoting changes compared to private fee-based wellness teams $(p<.05)$.
\end{abstract}

Conclusions: Identifying health-promoting policy, system and environment changes that are most readily implemented and sustained in child care centers can inform systems-level interventions and resource allocation related to early childhood obesity. This strategic planning process is a successful tool to translate sustainable changes related to healthy eating and physical activity, improve the quality rating of diverse child care centers, and promote healthy behaviors in early childhood.

Keywords: Policy, system, and environment change, Obesity prevention, Early childhood education, Intervention mapping, Quality rating

\section{Introduction}

Childhood obesity is a major epidemic in the United States with one in four preschool children being overweight or obese (CDC 2018). Five-year-old children who are overweight are four times more likely to become obese by eighth grade than normal weight children (Cunningham et al. 2014). This trend continues into adulthood and is associated 
with chronic diseases such as heart disease and diabetes (Pulgaron and Delamater 2014). Therefore, intervening in the first five years of life to address nutrition and physical activity-related behaviors that are carried long into adulthood is critical.

The number of children under six who spend an average of $30 \mathrm{~h}$ a week in non-parental care is over 11 million (Redford et al. 2017). This makes center-based care an important setting to focus early childhood obesity prevention efforts. Changing Policy, System, and Environmental (PSE) features focused on physical activity and healthy eating behaviors can play a key role in prevention strategies in early childhood education (ECE) settings because of their broad reach (all children in an ECE setting) and because they can be sustained over time, which allows for impact on children who enter the ECE setting year after year (de Silva-Sanigorski et al. 2010; LaRowe et al. 2016). In other words, making ongoing, foundational PSE changes can produce behavior changes that create longterm impacts (Larson 2011).

The implementation of health-promoting PSE practices can also positively impact the quality rating of ECE settings. Colorado Shines is an example of a Quality Rating Improvement System (QRIS) used in ECE centers across the state of Colorado. Through Colorado Shines, ECE programs are rated on quality in five categories, which includes "Child Health" (Colorado Shines 2015). The QRIS Child Health category is grounded in research and therefore, directly aligns with several healthy eating- and physical activityrelated PSE best practices. For example, "teachers leading at least two structured activities during outdoor play", and "serving meals family style" are PSE best practices that align with Colorado Shines ratings. Implementing health-promoting PSE changes not only fosters the adoption of healthy behaviors early in life, but also increases the quality of care provided in ECE settings, which collectively contributes to overall healthy child development (Britto et al. 2017).

Many recent obesity prevention interventions have focused on PSEs in the preschool environment. For example, the Active Early 2.0 program provided intervention preschools with curriculum materials, on and off-site training and technical assistance related to the implementation of health-promoting PSEs, and micro-grant support over 2 years (Tomayko et al. 2017). The program resulted in implementation of physical activity-related PSEs, including increasing minutes of outdoor play and staff-led physical activities per day, and teachers at intervention sites reported improvements in energy levels and improved behavior in children (Tomayko et al. 2017). Similarly, an increase in the physical activity of preschoolers and reduced adiposity was reported after an intervention which provided child care professionals with in-person training and a training manual aiming to increase PSEs related to structured and unstructured active play (Goldfield et al. 2016). The Nutrition and Physical Activity Self-Assessment for Child Care (NAP SACC) is another example of an intervention which guides child care settings in assessing, planning, and implementing nutrition and physical activity PSE best practices. Preschool centers that participated in the NAP SACC program reported improvements in nutrition and physical activity environments (Ammerman et al. 2007). Additionally, a significant increase in physical activity levels of preschool-aged children was reported following a 6-month NAP SACC intervention (Bonis et al. 2014).

A final intervention that incorporated the implementation of PSEs to address early childhood obesity prevention is the Culture of Wellness in Preschools (COWP) 
program, which is currently being implemented in over 120 ECE settings in Colorado (pending publication). The COWP program has five program components: classroombased nutrition education, classroom-based physical activity education, staff health promotion, a parent wellness workshop series component, and a strategic planning process, called the PSE change process, which is utilized to implement health-promoting PSE changes. Since 2012, the PSE change process has been successful in implementing an average of 4.7 PSE changes related to healthy eating and physical activity changes into ECE settings (Farewell et al. 2017).

The PSE change process is an evidence-based program that leads to the effective implementation of health-promoting PSE changes in ECE centers. However, there is a gap in the research related to specific healthy eating and physical activity PSE changes that are 'low hanging fruit', or that will be most readily implemented, and how implementation of these changes may impact the quality rating of ECE settings. Additionally, assessment of the implementation status of PSE changes in ECE settings over time is lacking. This study presents outcomes of the evidence-based PSE change process, specifically related to the most common types of health-promoting PSE changes implemented in ECE settings and sustainability of these changes 6 months after completion of the strategic planning process. These findings can be used to inform what types of PSE changes will be most impactful in ECE settings and how to tailor PSE interventions to ensure a long-term impact on physical activity and healthy eating behaviors, quality of care provided in ECE settings, and healthy child development.

\section{Materials and methods}

\section{Procedure}

The PSE change process is an adaptation of Intervention Mapping (Bartholomew et al. 1998) and is aligned with community-based participatory research principles (Belansky et al. 2011). Academic partners bring the latest evidence-based practices and program evaluation expertise to the community. The community partner brings experiential knowledge about the culture and baseline policies and procedures that are currently in place in the ECE setting. The PSE change process is also based on the socioecological model and the implementation of systems-level best practices in the development of sustainable interventions (Bartholomew et al. 1998).

This evidence-based process involves convening an ECE center-specific interdisciplinary wellness team comprising an average of five members including ECE providers, directors, education supervisors, and kitchen and human resources staff. The PSE facilitator leads the wellness team through 1-h meetings on a monthly basis (average: 6 meetings, range: 5-13 meetings) and utilizes three change-making strategies to implement PSE changes in ECE settings: (1) providers conduct a strengths and needs assessment of their center or home using a menu of evidence-based best practices related to current healthy eating and physical activity policies, systems and environmental features; (2) providers prioritize potential PSE changes based on importance and feasibility, and (3) providers develop action plans with specific action steps for implementation and sustainability of their highest priority PSE changes.

Each wellness team participant was given a binder that described the three key changemaking strategies, menus of best practices related to healthy eating and physical activity 
in ECE settings, and additional resources and materials. Healthy snacks were also provided at all wellness team meetings. The estimated cost per wellness team member was $\$ 20$, in addition to the $1 \mathrm{~h}$ per month allocated to participation in this intervention. Participating centers received $\$ 50 /$ classroom to support implementation of their selected PSE changes (e.g., speakers for outdoor play, outdoor play equipment, gardening supplies). Table 1 shows a summary of the three key change-making strategies involved in the PSE change process. Additional information about the PSE change process has also been previously published (Farewell et al. 2017).

\section{Participants}

University researchers met with the director at $68 \mathrm{ECE}$ centers to discuss the formation of an interdisciplinary wellness team between August 2015 and December 2016. A total of 43 wellness teams were formed representing 68 ECE centers in five large urban counties located in the front range of Colorado. Head Start-based, private fee-based and school-based ECE centers participated in the PSE change process. Head Start-based centers are administered by the Office of Head Start, within the Administration for Children and Families, U.S. Department of Health and Human Services and are designed to meet the needs of disadvantaged children (U.S. Department of Health and Human Services 2018). Private fee-based centers are independent, stand-alone licensed ECE centers. Public school-based centers are ECE centers that are located within a public school setting and are therefore affiliated with the school district (Kamerman and GatenioGabel 2007). Head Start agencies formed wellness teams at the agency delegate-level, with representation from each independent center within the agency. Many of the small public school-based centers formed wellness teams consisting of staff from two or three independent schools in similar geographic locations. The PSE change process was facilitated by four university staff, trained as PSE facilitators, with every interdisciplinary wellness team from August 2015 to August 2017.

\section{Instruments}

Characteristics of wellness teams and the ECE centers that they represent were collected by each PSE facilitator and entered into REDCap (Research Electronic Data Capture) electronic data capture tools hosted at the respective University. REDCap is a secure, web-based application designed to support data capture for research studies (REDCap

Table 1 The three key strategies that comprise the PSE change process

\begin{tabular}{|c|c|c|}
\hline Strategy & Purpose & Agenda items \\
\hline 1 & Conduct a strengths and needs assessment & $\begin{array}{l}\text { Identify strengths and areas of improvement } \\
\text { related to healthy eating and physical activity } \\
\text { PSEs currently in place } \\
\text { Review best practices } \\
\text { Identify possible PSE changes }\end{array}$ \\
\hline 2 & $\begin{array}{l}\text { Prioritize PSE changes based on importance and } \\
\text { feasibility }\end{array}$ & $\begin{array}{l}\text { Rate changes based on importance and feasibility } \\
\text { Select and finalize PSE changes }\end{array}$ \\
\hline 3 & Plan for action and develop sustainability plans & $\begin{array}{l}\text { Develop an action plan for each PSE change } \\
\text { Discuss dissemination of PSE changes } \\
\text { Create a sustainability plan }\end{array}$ \\
\hline
\end{tabular}


2009). Outcome data was collected via a post-only assessment tool. The director of every ECE center completed the PSE outcome assessment tool, which captured the number, type and status of PSE changes implemented. This was completed during the last PSE meeting and 6 months after the PSE change process. Directors reported if a PSE change was not implemented (PSE change not currently being implemented in center), partially implemented (PSE change being implemented in some classrooms and/or some days), or fully implemented (PSE change being implemented in all classrooms every day). The PSE facilitator tracked the status of PSE changes in REDcap. Approval for the study was obtained from the Colorado Multiple Institutional Review Board.

\section{Data analysis}

Descriptive statistics included the number of observations and percents for categorical data, and mean, standard errors and the ranges for continuous variables. The number and type of PSE changes implemented by ECE centers and sustained after 6 months were explored. A multivariable linear regression model was run to explore differences between types of ECE setting (e.g., Head Start-based, private fee-based, school-based) and the number of PSE changes implemented after completion of the PSE change process. $R^{2}$ and adjusted $R^{2}$ values, coefficients, standard errors, $t$ statistics and $p$-values for the multivariable linear regression model are presented. All analyses were performed in SPSS (IBM SPSS Inc. 2012) and a $p$-value of $<.05$ was considered significant.

\section{Results}

Table 2 displays the descriptive statistics for the participating ECE centers and wellness teams. Thirty-five percent (35\%) of centers were Head Start-based, 37\% were private fee-based, and $28 \%$ of preschool centers were part of a public school district. All ECE centers served low-income children and their families. All centers were located in urban counties; 28\% are located in the Denver Metro area, 23\% in El Paso County, 12\% in Weld County, 22\% in Pueblo County, and 15\% in Jefferson County. The 43 wellness teams ranged from representation of one singular center up to eight separate centers. The average size of the wellness team was 4.70 staff members $(S D=1.98$, range: $2-9)$ and the average size of the centers represented by the wellness teams was 50-79 preschool children enrolled. The average PSE change process was completed in 5.6 months ( $\mathrm{SD}=2.28$, range: $5-13$ ) and the director was on the wellness team $70 \%$ of the time.

Table 3 displays the healthy eating and physical activity-related PSE changes that were implemented across all ECE centers through participation in the PSE change process. All implemented PSE changes were selected from a baseline menu of best practices that each center identified were not in place prior to participation in the PSE change process. The three most common physical activity-related PSE changes implemented include: (1) a variety of portable play equipment is freely available to students during outdoor play (environmental-change) (59.7\%); (2) teachers lead at least two structured activities during outdoor play (policy change) (50\%), and (3) physical activity-related messaging is displayed around the preschool center (environmentalchange) (38.7\%). The three most common healthy-eating-related PSE changes implemented include: (1) water is readily accessible in all indoor and outdoor environments (environmental-change) (58.1\%); (2) centers have a school garden/seed-to-table 
Table 2 Demographics ( $n=43$ wellness teams representing 68 ECE centers)

\begin{tabular}{lll}
\hline ECE centers $(\boldsymbol{n}=\mathbf{6 8})$ & $\boldsymbol{n}$ & \% \\
\hline Childcare center type & 24 & 35 \\
Head Start-based & 25 & 37 \\
Private fee-based & 19 & 28 \\
School-based & & 28 \\
Childcare center location & 19 & 15 \\
Denver County & 10 & 23 \\
Jefferson County & 16 & 22 \\
El Paso County & 15 & 12 \\
Pueblo County & 8 & $\%$ \\
Weld County & $\boldsymbol{n}$ & \\
\hline Wellness teams ( $=\mathbf{4 3}$ ) & & 30 \\
\hline Director presence on wellness team & 13 & 70 \\
No & 30 & $\mathbf{s d}$ \\
Yes & $\boldsymbol{m}$ & 1.98 \\
\hline & 4.70 & 0.86 \\
\hline Size of wellness team & 3.21 & 2.28 \\
Size of center & 5.60 & \\
Length of process (months) & & \\
\hline
\end{tabular}

education and children eat produce from the garden (environmental-change) (45.2\%), and (3) healthy eating-related messaging is displayed throughout the preschool center (environmental-change) (27.4\%).

Table 4 displays the number of changes implemented and sustainability of changes 6 months after completion of the PSE change process based on director report by type of child care setting. The average number of director-reported PSEs implemented by center was 4.67 for Head Start centers, 5.54 for private fee-based centers, and 4.74 for public school-based centers. Overall, directors reported that an average of 5.07 changes were implemented at each ECE center. Six months after completion of the PSE change process, $52 \%$ of changes were partially implemented and $45 \%$ of changes were fully implemented in Head Start centers, $43 \%$ of changes were partially implemented and $47 \%$ of changes were fully implemented in private fee-based centers, and $42 \%$ of changes were partially implemented and $47 \%$ of changes were fully implemented in school-based centers. Across all ECE centers, directors reported that $11 \%$ of PSE changes were not implemented, 42\% were partially implemented, and 47\% were fully implemented 6 months after completion of the PSE change process.

Linear regression model results are presented in Table 5 with the number of PSE changes implemented after completion of the PSE change process as the primary outcome variable. The full model explained $17.6 \%$ of the variation in the number of PSE changes implemented by wellness team after completion of the PSE change process $(F=2.49, p<.05)$. Head Start-based wellness teams implemented 1.52 fewer changes after completion of the PSE change process compared to the private fee-based wellness teams $(t=-2.22, p<.05)$, controlling for all other variables in the model. No other factors were significantly associated with the number of changes implemented. 
Table 3 Physical activity and healthy eating-related PSE changes implemented by ECE centers ( $n=68$ ECE centers)

\begin{tabular}{|c|c|c|c|c|c|}
\hline $\begin{array}{l}\text { Physical activity- } \\
\text { related PSE change }\end{array}$ & Type of change & $\%$ of centers & $\begin{array}{l}\text { Healthy eating- } \\
\text { related PSE change }\end{array}$ & Type of change & $\%$ of centers \\
\hline $\begin{array}{l}\text { A variety of portable } \\
\text { play equipment ( } 3 \\
\text { or more different } \\
\text { types) is always } \\
\text { freely available to } \\
\text { students }\end{array}$ & Environment & 59.7 & $\begin{array}{l}\text { Water is readily } \\
\text { accessible in all } \\
\text { indoor and out- } \\
\text { door environments }\end{array}$ & Policy & 58.1 \\
\hline $\begin{array}{l}\text { Teachers lead chil- } \\
\text { dren in at least } 2 \\
\text { structured physical } \\
\text { activities/day }\end{array}$ & Policy & 50.0 & $\begin{array}{l}\text { Centers have a } \\
\text { school garden } \\
\text { and seed-to-table } \\
\text { education is incor- } \\
\text { porated into the } \\
\text { curriculum }\end{array}$ & Environment & 45.2 \\
\hline $\begin{array}{l}\text { PA messaging } \\
\text { is displayed in } \\
\text { classrooms and } \\
\text { common areas }\end{array}$ & Environment & 38.7 & $\begin{array}{l}\text { HE messaging } \\
\text { is displayed in } \\
\text { classrooms and } \\
\text { common areas }\end{array}$ & Environment & 27.4 \\
\hline $\begin{array}{l}\text { Music and Move- } \\
\text { ment activities are } \\
\text { implemented at } \\
\text { least once/day }\end{array}$ & System & 37.1 & $\begin{array}{l}\text { Nutrition education } \\
\text { and cooking activi- } \\
\text { ties are included } \\
\text { in lesson plans at } \\
\text { least once/month }\end{array}$ & System & 27.4 \\
\hline $\begin{array}{l}\text { PA education is } \\
\text { provided to } \\
\text { children by using a } \\
\text { standardized cur- } \\
\text { riculum } \geq 1 \text { time } \\
\text { per week }\end{array}$ & Policy & 12.9 & $\begin{array}{l}\text { Special occasions are } \\
\text { celebrated with } \\
\text { healthy food or } \\
\text { non-food activities }\end{array}$ & Policy & 16.1 \\
\hline $\begin{array}{l}\text { Screen time is not } \\
\text { used as a reward }\end{array}$ & Policy & 8.1 & $\begin{array}{l}\text { All food and bever- } \\
\text { ages served at } \\
\text { events meet the } \\
\text { nutrition standards } \\
\text { of the CACFP } \\
\text { program }\end{array}$ & Policy & 12.9 \\
\hline $\begin{array}{l}\text { Parents are provided } \\
\text { with information } \\
\text { and reminders to } \\
\text { dress their children } \\
\text { in clothing that } \\
\text { permits easy and } \\
\text { safe movement }\end{array}$ & System & 6.5 & $\begin{array}{l}\text { Children participate } \\
\text { in monthly food } \\
\text { preparation activi- } \\
\text { ties }\end{array}$ & System & 8.1 \\
\hline $\begin{array}{l}\text { Outdoor playtime is } \\
\text { not withheld for } \\
\text { poor behavior }\end{array}$ & Policy & 6.5 & $\begin{array}{l}\text { Meals are served } \\
\text { family style }\end{array}$ & Policy & 6.5 \\
\hline $\begin{array}{l}\text { Short activity ses- } \\
\text { sions (10-15 min) } \\
\text { using varied } \\
\text { movements are } \\
\text { implemented daily }\end{array}$ & System & 6.5 & $\begin{array}{l}\text { Staff encourage } \\
\text { conversation and } \\
\text { use enthusiastic } \\
\text { modeling of food } \\
\text { during meal times }\end{array}$ & System & 4.8 \\
\hline $\begin{array}{l}\text { Children have 2-3 } \\
\text { opportunities } \\
\text { for outdoor play } \\
\text { (60-90 min) per } \\
\text { day }\end{array}$ & Policy & 4.8 & $\begin{array}{l}\text { A variety of common } \\
\text { and novel fruits } \\
\text { and vegetables are } \\
\text { included in menus }\end{array}$ & Environment & 4.8 \\
\hline $\begin{array}{l}\mathrm{PA} \text { is not used as a } \\
\text { punishment }\end{array}$ & Policy & 1.6 & $\begin{array}{l}\text { Nutrition lessons } \\
\text { reflect children's } \\
\text { culture }\end{array}$ & System & 4.8 \\
\hline
\end{tabular}


Table 3 (continued)

\begin{tabular}{|c|c|c|c|c|c|}
\hline $\begin{array}{l}\text { Physical activity- } \\
\text { related PSE change }\end{array}$ & Type of change & $\%$ of centers & $\begin{array}{l}\text { Healthy eating- } \\
\text { related PSE change }\end{array}$ & Type of change & $\%$ of centers \\
\hline $\begin{array}{l}\text { Screen time is } \\
\text { limited to no more } \\
\text { than } 30 \text { min per } \\
\text { week and is used } \\
\text { for education or } \\
\text { physical activities } \\
\text { only }\end{array}$ & Policy & 1.6 & $\begin{array}{l}\text { Staff sit with children } \\
\text { during meals and } \\
\text { snacks and eat the } \\
\text { same food }\end{array}$ & System & 4.8 \\
\hline $\begin{array}{l}\text { Children are not } \\
\text { sedentary for more } \\
\text { than } 60 \text { min at a } \\
\text { time except when } \\
\text { sleeping }\end{array}$ & System & 1.6 & $\begin{array}{l}\text { Food is not used as a } \\
\text { reward or punish- } \\
\text { ment }\end{array}$ & Policy & 1.6 \\
\hline $\begin{array}{l}\text { Families are provided } \\
\text { resources related } \\
\text { to limiting screen } \\
\text { time }\end{array}$ & System & 1.6 & $\begin{array}{l}\text { Outside food is not } \\
\text { allowed in the } \\
\text { classroom }\end{array}$ & Policy & 1.6 \\
\hline
\end{tabular}

Table 4 Implementation and sustainability of PSE changes by ECE center setting

\begin{tabular}{|c|c|c|c|c|c|c|c|}
\hline \multirow[t]{2}{*}{ ECE center setting } & \multirow[t]{2}{*}{$\begin{array}{l}\text { Number } \\
\text { of centers }\end{array}$} & \multirow{2}{*}{$\begin{array}{l}\text { Number } \\
\text { of wellness } \\
\text { teams }\end{array}$} & \multirow[t]{2}{*}{$\begin{array}{l}\text { Total PSE } \\
\text { changes }\end{array}$} & \multirow[t]{2}{*}{$\begin{array}{l}\text { Average } \\
\text { PSEs/center }\end{array}$} & \multicolumn{3}{|c|}{$\begin{array}{l}6 \text { month-level } \\
\text { of implementation (\%) }\end{array}$} \\
\hline & & & & & Not & Partially & Fully \\
\hline Head Start-based & 24 & 5 & 112 & 4.67 & 3 & 52 & 45 \\
\hline Private fee-based & 25 & 25 & 143 & 5.54 & 10 & 43 & 47 \\
\hline Public school-based & 19 & 13 & 90 & 4.74 & 25 & 28 & 47 \\
\hline Totals & 68 & 43 & 345 & 5.07 & 11 & 42 & 47 \\
\hline
\end{tabular}

Table 5 Multivariable linear regression model: factors that predict the number of PSE changes implemented after completion of the PSE change process ( $n=43$ wellness teams)

Outcome: number of PSE changes implemented after completion of the PSE change process

\begin{tabular}{lllllllll}
\hline & $\boldsymbol{R}^{\mathbf{2}}$ & $\mathbf{A d j} \boldsymbol{R}^{\mathbf{2}}$ & $\mathbf{F}$ statistic & $\boldsymbol{p}$-value & $\boldsymbol{\beta}$ & SE of $\boldsymbol{\beta}$ & $\boldsymbol{t}$ statistic & $\boldsymbol{p}$-value \\
\hline & .29 & .18 & 2.49 & .04 & & & & \\
Size of wellness team & & & & & .06 & .11 & .60 & .56 \\
Length of process & & & & & .14 & .08 & 1.8 & .08 \\
Director presence & & & & & .77 & .62 & 1.25 & .22 \\
Center size & & & & .29 & .24 & 1.24 & .22 \\
Center type & & & & & & & \\
School-based & & & & -.93 & .71 & -1.30 & .20 \\
Head Start-based & & & & & -1.52 & .68 & -2.22 & $.03^{*}$ \\
\hline
\end{tabular}

a Reference category for center type is private fee-based ECE centers; ${ }^{*} p<.05$

\section{Discussion}

The PSE change process is an evidence-based strategic planning process that leads to the implementation of health-promoting policy, system and environment changes in diverse ECE settings (Belansky et al. 2011; Farewell et al. 2017). The PSE change process was implemented with 43 wellness teams representing 68 ECE centers throughout Colorado. 
The average number of healthy eating- and physical activity-related PSE changes implemented by each preschool center after completion of the process was 5.07. Of the top six most commonly selected PSE changes, five were environmental changes.

Policy changes may be more challenging than environmental changes to implement in ECE centers. Fagen et al. (2014) found policy changes to be a common barrier to PSE work in school-based centers. School staff and others involved in PSE work stated that resistance from administration and stakeholders was a challenge to implementing policy changes in their ECE center. Further, respondents felt policy change was an "unfamiliar, and high stakes approach" (Fagen et al. 2014). PSE interventions in ECE centers have also resulted in lower implementation of policy changes compared to environmental and system changes. A low-intensity, state-wide, professional development program designed to support early childhood professionals in modeling healthy behaviors found no significant changes in policies related to healthy eating and physical activity; however, implementation of environment and system changes led to improvements in children's healthy eating behaviors (Hardy et al. 2010). This suggests that environment and systemlevel changes may be more readily implemented and sustained in ECE centers.

Overall, directors reported that $42 \%$ of PSE changes were partially implemented at 6 months and $47 \%$ of changes were fully implemented at 6 months. While some studies have examined implementation of wellness policies in various school settings, few studies assessed sustainability of changes over time (Sánchez et al. 2014). These findings suggest that the PSE change process leads to sustainable change with approximately $89 \%$ of changes at least partially or fully sustained 6 months after the intervention. Too often school-based interventions lack the ability to impact sustainable and ongoing change (Cauchi et al. 2016). The PSE change process may be a powerful tool for increasing the implementation and sustainability of health-promoting best practices into ECE settings leading to ongoing behavior change.

The type of ECE setting was significantly associated with the number of PSE changes implemented by the wellness team after completion of the PSE change process. Head Start-based wellness teams implemented significantly fewer changes compared to private fee-based wellness teams; however, Head Starts also reported that more changes were partially or fully implemented after 6 months compared to private fee- and schoolbased centers. Head Start centers may have a higher number of health-promoting PSEs implemented prior to initiation of the PSE change process because Head Start program regulations mandate policies such as nutritional and health services, outdoor play, and parent engagement for health (U.S. Department of Health and Human Services 2018). For example, ensuring that water is readily accessible for children throughout the school day is a Head Start requirement that also aligns with the PSE change process best practice menu. This may result in lower numbers of new PSE changes selected and implemented. Head Start centers may also have additional resources to support the sustainability of the selected changes compared to private fee-based and school-based ECE centers (Kamerman and Gatenio-Gabel 2007).

Most of the most commonly selected PSE changes align with the Early Childhood Environment Rating Scale (ECERS), which is used in Colorado to inform the Colorado Shines Quality Rating of an ECE center or home. ECE programs must complete an ECERs assessment and receive a rating prior to receiving a Colorado Shines score. 
Minimum ECERS ratings are required for a program to receive certain Colorado Shines levels (i.e., no classrooms can have an ECERS rating below 3.75 to receive a level $3 \mathrm{Col}$ orado Shines rating). ECERS includes seven subscales, many of which are related to healthy eating and physical activity PSE best practices. Within each subscale are several items which have indicators ranked levels 1, 3, 5, and 7 (Harms et al. n.d.). One example of a level 7, or an "Excellent", indicator is, "Classroom teachers lead children in structured physical activities daily", which was selected by $50 \%$ of ECE centers after participation in the PSE change process (Colorado Shines 2015). Therefore, implementation of sustainable PSE changes has the potential to improve the quality rating of an ECE setting, which results in positive outcomes related to healthy behaviors and development in early childhood (Britto et al. 2017).

\section{Limitations}

This study had some limitations. ECE providers experience a high annual turn-over rate. If centers experience a director turnover after completion of the PSE change process, the outcome evaluation may be completed by someone who did not participate in the wellness team and/or is new to the center and may not be familiar with the wellness policies in place. In addition, the status of changes is captured via director self-report, which may yield biased results. Finally, the sample size for this study was small, resulting in low statistical power potentially minimizing the ability to detect significant findings in the linear regression model. This model will be re-run as the PSE change process continues to be facilitated with wellness teams throughout Colorado.

\section{Conclusions}

Identifying health-promoting PSE changes that are most readily implemented and sustained in Head Start-, private fee-, and school-based ECE centers can inform PSE interventions and resource allocation related to early childhood obesity. Findings from this study suggest the following: (1) ECE centers may be more likely to implement healthpromoting environmental changes compared to policy changes due to perceived barriers surrounding policy changes including administrative resistance; (2) Head Start-based wellness teams implemented significantly fewer health-promoting PSE changes compared to private fee-based centers, which may be explained by a higher number of best practices met at baseline due to Head Start regulations and requirements, and (3) the PSE change process is a successful tool to translate sustainable PSE changes related to healthy eating and physical activity, which may in turn lead to improvements in the quality rating of diverse ECE centers and promote healthy behaviors in early childhood.

\section{Abbreviations}

ECE: Early childhood education; PSE: Policy, system, environment; QRIS: Quality rating improvement system; NAPSACC : Nutrition and Physical Activity Self-Assessment for Child Care; COWP: Culture of Wellness in Preschools; ECERS: Early Childhood Environment Rating Scale.

Acknowledgements

The authors sincerely thank all the ECE providers and centers who participated in this study.

Authors' contributions

This article is original work. The article has not received prior publication and is not under consideration for publication elsewhere. CF drafted the body of the manuscript. CF, EM, and JNP collected the data. SS and JQ helped to analyze the data. JP reviewing the manuscript and provided final edits. All authors have seen and approve the manuscript being submitted. All authors read and approved the final manuscript. 


\section{Funding}

This study was funded by the Colorado Health Foundation under grant (CHF-6471, Dr. Jini Puma); and the Colorado Department of Health and Human Services (CMS\#84020, Dr. Jini Puma).

\section{Data availability}

The datasets used and/or analyzed during the current study are available from the corresponding author on reasonable request.

\section{Competing interests}

All authors declare that they have no competing interests.

Received: 18 September 2019 Accepted: 6 May 2020

Published online: 11 May 2020

\section{References}

Ammerman, A. S., Ward, D. S., Benjamin, S. E., Ball, S. C., Sommers, J. K., Molloy, M., et al. (2007). An intervention to promote healthy weight: Nutrition and Physical Activity Self-Assessment for Child Care (NAP SACC) theory and design. Preventing Chronic Disease, 4(3), A67.

Bartholomew, L. K., Parcel, G. S., \& Kok, G. (1998). Intervention mapping: A process for developing theory and evidencebased health educationp. Health Education \& Behavior, 25(5), 545-563. https://doi.org/10.1177/109019819802500 502.

Belansky, E. S., Cutforth, N., Chavez, R. A., Waters, E., \& Bartlett-Horch, K. (2011). An adapted version of intervention mapping (AIM) is a tool for conducting community-based participatory research. Health Promotion Practice, 12(3), 440-455. https://doi.org/10.1177/1524839909334620.

Bonis, M., Loftin, M., Ward, D., Tseng, T. S., Clesi, A., \& Sothern, M. (2014). Improving physical activity in daycare interventions. Childhood Obesity, 10(4), 334-341. https://doi.org/10.1089/chi.2014.0040.

Britto, P. R., Lye, S. J., Proulx, K., Yousafzai, A. K., Matthews, S. G., Vaivada, T., et al. (2017). Nurturing care: promoting early childhood development. The Lancet, 389(10064), 91-102. https://doi.org/10.1016/S0140-6736(16)31390-3.

Cauchi, D., Glonti, K., Petticrew, M., \& Knai, C. (2016). Environmental components of childhood obesity prevention interventions: an overview of systematic reviews. Obesity Reviews, 17(11), 1116-1130. https://doi.org/10.1111/obr.12441.

Centers for Disease Control (CDC) (2018). Spectrum of Opportunities for Obesity Prevention in the Early Care and Education Setting (ECE) CDC Technical Assistance Briefing Document. Retrieved from https://www.cdc.gov/obesity/ downloads/spectrum-of-opportunities-obesity-prevention.pdf.

Colorado Shines (2015). Colorado Shines Program Guide. Available at: https://www.coloradoshines.com/resource/14406 07605000/asset_pdfs1/asset_pdfs1/ColoradoShinesProgramGuide.pdf. Accessed 15 June 2019).

Cunningham, S. A., Kramer, M. R., \& Narayan, K. M. V. (2014). Incidence of childhood obesity in the United States. New England Journal of Medicine, 370(5), 403-411. https://doi.org/10.1056/NEJMoa1309753.

de Silva-Sanigorski, A. M., Bell, A. C., Kremer, P., Nichols, M., Crellin, M., Smith, M., et al. (2010). Reducing obesity in early childhood: results from Romp Chomp, an Australian community-wide intervention program. The American Journal of Clinical Nutrition, 91(4), 831-840. https://doi.org/10.3945/ajcn.2009.28826.

Fagen, M. C., Asada, Y., Welch, S., Dombrowski, R., Gilmet, K., Welter, C., et al. (2014). Policy, systems, and environmentally oriented school-based obesity prevention: Opportunities and challenges. Journal of Prevention and Intervention in the Community, 42(2), 95-111. https://doi.org/10.1080/10852352.2014.881175.

Farewell, C. V., Puma, J. E., Powers, J., \& Belansky, E. S. (2017). Assess, Identify, Make it Happen (AIM) for Preschools: A Tool to Decrease Early Childhood Obesity. Health Promotion Practice. https://doi.org/10.1177/1524839917746677.

Goldfield, G. S., Harvey, A. L. J., Grattan, K. P., Temple, V., Naylor, P. J., Alberga, A. S., et al. (2016). Effects of child care intervention on physical activity and body composition. American Journal of Preventive Medicine, 51(2), 225-231. https://doi. org/10.1016/j.amepre.2016.03.024.

Hardy, L. L., King, L., Kelly, B., Farrell, L., \& Howlett, S. (2010). Munch and move: evaluation of a preschool healthy eating and movement skill program. International Journal of Behavioral Nutrition and Physical Activity, 7(1), 80. https://doi. org/10.1186/1479-5868-7-80.

Harms, T., Clifford, R. M., \& Cryer, D. (n.d.). Early Childhood Environment Rating Scale. Retrieved from https://books.goog e.co.nz/books?hl=en\&lr=\&id=GOsZBQAAQBAJ\&oi=fnd\&pg=PP1\&dq=Offer+a+variety+of+developmen tally+appropriate+materials/toys +that+challenge+children+and+capture+their+interest.\&ots $=0 \mathrm{gZrC}$ r $43 \mathrm{e} 7 \mathrm{f}$ $\&$ sig=ZPzh5jP5ulRV7RfJhwR98gOwEUI\#v=onepage\&q\&f=false.

IBM SPSS Inc. (2012). SPSS Statistics for Windows. IBM Corp. Released 2012, Version 20, 1-8.

Kamerman, S. B., \& Gatenio-Gabel, S. (2007). Early childhood education and care in the United States: An overview of the current policy picture. International Journal of Child Care and Education Policy, 1(1), 23-34. https://doi. org/10.1007/2288-6729-1-1-23.

LaRowe, T. L., Tomayko, E. J., Meinen, A. M., Hoiting, J., Saxler, C., Cullen, B., et al. (2016). Active early: one-year policy intervention to increase physical activity among early care and education programs in Wisconsin. BMC Public Health, 16(1), 607. https://doi.org/10.1186/s12889-016-3198-3.

Larson, N., Ward, D. S., Neelon, S. B., \& Story, M. (2011). What role can child-care settings play in obesity prevention? A review of the evidence and call for research efforts. Journal of the American Dietetic Association, 111(9), $1343-1362$. https://doi.org/10.1016/j.jada.2011.06.007.

Pulgaron, E. R., \& Delamater, A. M. (2014). Obesity and type 2 diabetes in children: Epidemiology and treatment. Current Diabetes Reports, 14(8), 508. https://doi.org/10.1007/s11892-014-0508-y. 
Redford, J., Desrochers, D., Hoyer, K. M., \& Ralph, J. (2017). Stats in brief: The years before school: Children's nonparental care arrangements from 2001 to 2012. Retrieved from https://nces.ed.gov/pubs2017/2017096.pdf.

Research electronic data capture (REDCap)—A metadata-driven methodology and workflow process for providing translational research informatics support. (2009). Journal of Biomedical Informatics, 42(2), 377-381. https://doi. org/10.1016/J.JBI.2008.08.010

Sánchez, V., Hale, R., Andrews, M., Cruz, Y., Bettencourt, V., Wexler, P., et al. (2014). School wellness policy implementation. Health Promotion Practice, 15(3), 340-348. https://doi.org/10.1177/1524839912450878.

Tomayko, E. J., Prince, R. J., Hoiting, J., Braun, A., LaRowe, T. L., \& Adams, A. K. (2017). Evaluation of a multi-year policyfocused intervention to increase physical activity and related behaviors in lower-resourced early care and education settings: Active Early 2.0. Preventive Medicine Reports, 8(Supplement C), 93-100. https://doi.org/10.1016/j.pmedr .2017.08.008.

U.S. Department of Health and Human Services. (2018). History of Head Start | Office of Head Start | ACF. Retrieved April 19, 2018, from https://www.acf.hhs.gov/ohs/about/history-of-head-start.

\section{Publisher's Note}

Springer Nature remains neutral with regard to jurisdictional claims in published maps and institutional affiliations.

\section{Submit your manuscript to a SpringerOpen ${ }^{\circ}$} journal and benefit from:

- Convenient online submission

- Rigorous peer review

- Open access: articles freely available online

- High visibility within the field

Retaining the copyright to your article

Submit your next manuscript at $\gg$ springeropen.com 